\title{
The Troubles of Cross-border E-commerce Enterprises_taking the Southeast Asian Market as an Example
}

\author{
Xingxing Lu, Qiong Long* \\ Business school, Beijing Institute of Fashion Technology, Chaoyang District, Beijing, China \\ 627525960@qq.com,sxylqiong@bift.edu.cn \\ *Corresponding Author: Emails: sxylqiong@bift.edu.cn
}

Keywords: Cross-border e-commerce, ASEAN countries, Enterprises, Logistics, Troubles.

\begin{abstract}
According to the presentations of cross-border e-commerce industry and enterprise representatives attending the cross-border e-commerce service enterprise symposium, through the study and understanding of relevant literature and industry news, combined with the "four-eighth new policy" and the status quo of the industry, mainly Take ASEAN countries as an example to summarize the troubles faced by cross-border e-commerce companies and propose improvements. It is hoped that through the understanding and analysis of the status quo of China's cross-border e-commerce frontier enterprises, this study will find out the problems that are currently faced, and provide reference for the further development of cross-border e-commerce enterprises in China.
\end{abstract}

\section{Current Status of Cross-Border E-Commerce Industry}

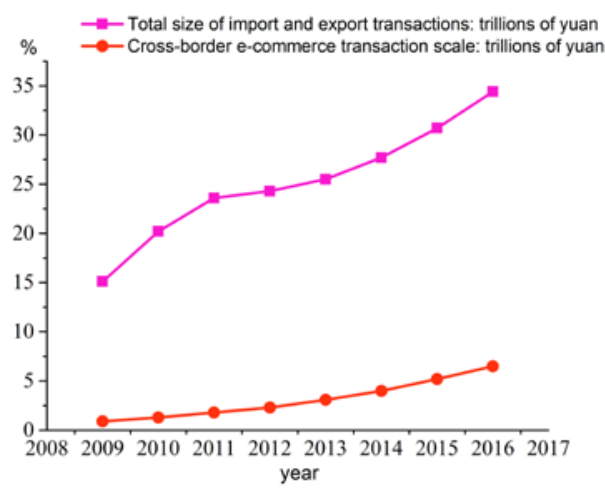

Figure 1 Cross-border e-commerce scale and growth rate in 20092016.

With the strict control of the quality of its own products by cross-border e-commerce companies and the improvement of product coverage by cross-border e-commerce platforms, consumers' trust in online shopping has been increased, international purchasing power has also increased, and cross-border e-commerce is banned. Offline trading has become the mainstream of trading models. As shown in Figure 1, the scale of cross-border e-commerce transactions in China has been on the 
rise from 2009 to 2016. In 2015, cross-border e-commerce accounted for 22\% of China's international trade, accounting for more than $27 \%$ in 2016. It is expected to account for more than 37\% in 2020 (Kedi Song, 2018). However, under the optimistic trend of the megatrend, China's cross-border e-commerce still has unresolved issues. According to the statements of relevant leaders of cross-border e-commerce frontier enterprises, there are still many troubles at the current cross-border e-commerce enterprises.

\section{Domestic Cross-Border E-Commerce Leading Enterprise Troubles Collection}

The guests at the symposium were all leading companies in China's cross-border e-commerce industry. Alibaba, Jingdong, Netease koala, Suning overseas purchase, Gome overseas purchase, Jumei Premium, Xiaohongshu, Siku, cross Representatives from companies such as Gangtong. During the symposium, the companies stated the current status of the company, the difficulties encountered, and the views on the industry and national policies. After discussion, it was found that the current problems faced by cross-border e-commerce companies are mainly concentrated in the following aspects.

\subsection{Lagging behind Logistics in Backward Areas}

In terms of logistics, there is a problem of lagging logistics in backward areas, and the return of goods can only be digested internally. For example, in Southeast Asia, some developed regions are unable to transport through local logistics. They can only be transported by means of postal services such as postal services. The cost is relatively high, which makes it difficult for some small enterprises to ensure balance of payments. On the issue of return, Suning Global, Netease Koala and other corporate leaders have mentioned that when the platform encounters self-operated return problems, under normal circumstances, the goods cannot be returned to the bonded area. A very important reason is that people in the bonded area generally have no way to identify whether the returned goods are genuine or not. There are problems such as increased workload, insufficient professionalism and insufficient experience. Therefore, most of the time, the goods are directly returned to the company headquarters. However, such returned goods can not be put on the platform for sale again, and can only be digested within the enterprise, or a special return department is established. Most of the time, it is cheap to sell to internal employees, so there will be some loss in the income. So far, the issue of returns is a common problem in exporting overseas.

However, on this issue, Jumei Premium has a set of its own service process, which is a good way to reduce the risk of return. Since most of the products sold by Jumei Premium are cosmetics, users may have skin allergies, etc., so before determining the supplier, the company will set up a special appraisal team to identify the supplier's products and the supplier's qualifications are reviewed, and formal partnerships are established with them after they are qualified. All goods sold are consolidated into the bonded area and sold to all parts of the country. The strict control of quality in the early stage greatly reduced the occurrence of late return accidents.

\subsection{Inconvenience of Payment}

In Southeast Asia, many developing countries and underdeveloped areas where the Internet has just started have great difficulties in the payment process. Not every country is like China. The use of Alipay and WeChat is very common. It is not so convenient for many overseas countries to pay. Many times, there are certain problems in online payment. The deputy general manager of Beijing Cross-Hong Kong International Trade Co., Ltd. mentioned that the cooperative enterprises use local banks to transfer funds to the domestic market through certain channels, and then transfer to the 
enterprise, which will undergo a complicated transfer process. There are also many problems with the docking of local banks. Even in many cases, money can only be sent through the gray channel. The head of Tmall International of Alibaba Group also said that because the company had expected a few years ago to gain an opportunity to develop the industry and get a foreign payment license in advance, there are not many problems in payment.(Fuxiong Yan, 2017) But for most companies that don't get a payment license, international payments are still a headache.

\subsection{Tariff Barriers}

Although economic globalization is a major trend in economic development, tariff barriers are still a major annoyance for cross-border e-commerce. According to the description of the heads of participating companies, in countries and regions such as Japan and Europe, trade protection in many countries is more serious than in China. And after the Sino-US trade war, it has a great negative impact on cross-border e-commerce. The volume of the four major express delivery in most regions has increased dramatically, which has caused the company to lose a lot of time. And cross-border tax rates are not dominant. Many products, even if the platform is willing to do it, will choose to give up due to cost considerations, which will result in a certain impact on product diversity.

\subsection{Policy Lag}

Whether the lag of some domestic policies has a positive effect on the development of the industry remains to be seen. For instance, many enterprises mentioned the subsidy policy of customs clearance of 1,000 yuan. Many enterprises want to avoid tariffs, or they do not want to pass the customs when the data is too transparent, evading official statistics, will voluntarily give up this subsidy, so the customs according to the 9610 and 1210 mode statistics The data obtained has great limitations. On this issue, many companies have called on the government to provide clear policy guidance to cross-border e-commerce companies, especially SMEs, such as training related talents and promoting the development of the industry. Many companies mentioned the issue of import quotas. The single transaction limit for cross-border e-commerce retail imports was RMB 2,000 and the annual transaction limit of RMB 20,000 was questioned. Some modifications should be made to ensure that they keep pace with the times. For example, the elimination of the single limit of imported goods only stipulates the limit for the purchase of goods throughout the year, which can also guarantee people's yearning for a better life to a certain extent.

\section{The Status of Import and Export of Cross-Border E-Commerce Enterprises in Southeast Asia}

According to feedback from corporate statistics, the import and export of Southeast Asia is in a period of rapid rise and has great potential. Cross-border e-commerce activities are currently concentrated in Thailand, Vietnam, Malaysia, Indonesia and Cambodia. Among them, there are more rubber products in Thailand, more brewed drinks and snack foods in Vietnam and Malaysia, and more rice in Cambodia. According to the person in charge of Suning's overseas supply chain, Suning's overseas performance totaled 3.02 million units during the two years from August 2016 to June 2018, with a turnover of 158 million yuan, an average of 3.53 million yuan per month. The transaction volume, which is mainly based on health products, brewed drinks, rice and instant snacks, but the consumption of ASEAN still only accounts for a small part. So far, the turnover of ASEAN Tesco has not exceeded 150 million. Yuan Renminbi, the self-operated sector is still dominated by Japan, Europe and the United States and Australia. Alibaba is mainly invested in 
Lazada online shopping site in Southeast Asia. The logistics is supported by Alibaba's rookie. The technology is supported by Alibaba Group. The target users are mainly in Thailand, Malaysia, Indonesia and the Philippines. The export is based on Yidatong. For example, Alibaba's cooperation in Malaysia is mainly achieved through a Datong (Jianghai Hong, 2018). The heads of various enterprises said that the underlying foundation of Southeast Asia is relatively good. Although there is a certain gap between developed countries such as Japan and Europe and the United States, the population base in Southeast Asia is large, and import and export have great potential for development.

\section{The Impact of the "48th New Deal" on Cross-border E-commerce Imports}

In order to create a relatively fair market competition environment and make cross-border e-commerce develop healthier and orderly, on April 8, 2016, China proposed a new tax system for cross-border e-commerce retail (B2C) imports. Goods traded through cross-border e-commerce will no longer be subject to postage tax on postal items, but will be subject to customs duties and import value-added tax and consumption tax (Liming Geng, 2016).

The April Eighth New Deal mainly played a regulatory role. According to the problems encountered by the leaders of various enterprises in the implementation of the actual policy, they believe that the New Deal of the 48th is mainly regulated and restricted in two aspects. One is the taxation aspect. Some enterprises believe that policies such as the individual 50-yuan exemption point will have corresponding countermeasures such as splitting operations when they are implemented, which makes this policy lose its meaning. The other is the regulatory level, which is divided into personal item supervision and cargo supervision. The regulation of goods has caused the industry to melt to a certain extent, which is not conducive to the development of the industry. Therefore, most companies hope to strengthen the supervision of personal items, but the supervision of taxation can be changed to the method of collecting comprehensive taxes, which may be more conducive to the implementation and implementation of the policy, and the effect of supervision will be better. Promote the cross-border e-commerce industry in the true sense.

During the implementation of the "March 8 New Deal", the impact of the whitelist system was the biggest. On the positive side, the whitelist system has a relatively large marketing promotion effect for cross-border e-commerce companies with bonded import and direct mail models as the main methods, such as restricting the growth of cross-border e-commerce category to a large extent. To a certain extent, it limits the efficiency of foreign goods and brands entering China, and it will also make more and more consumers return to the old road of overseas procurement. This is not a sensible behavior. However, some enterprises believe that the implementation of the "four-eighth new policy" will make cross-border e-commerce more standardized, but in the specific implementation process of the policy, some reasonable adjustments according to the actual situation are prerequisite.

\section{Conclusion}

In view of the differences in marketing models and products of cross-border e-commerce platforms, cross-border e-commerce platforms such as Jumei Premium Co., Ltd. rely on short and fast rules to sell explosive products; platforms such as Xiaohongshu rely on consumer word-of-mouth and Data to customize products, experiential promotion, and accurate consumption; Alibaba's Tmall International, Jingdong Group's global purchase, Suning's global purchase platform have own logistics warehouses to maintain the various operations through self-operated models. Each cross-border e-commerce platform should also screen out specific international growth businesses, grasp market trends according to relevant policies, and take advantage of the 
development potential of the international market. Enterprises can learn from each other and face troubles and difficulties together. Domestic relevant policies must also be reformed in a timely manner, adapting to changes in the industry, and truly promoting the development of cross-border e-commerce industry.

\section{References}

[1] Fuxiong, Yan, 2017. Analysis of the Problems and Countermeasures of Cross-border E-commerce in Tmall International, Science and Technology Wind. (18), pp.300-301.

[2] Jianghai, Hong, 2018. Alibaba B2B e-commerce marketing strategy research, Western leather. (2), pp.13-14.

[3] Liming, Geng, 2016. "The April Eighth New Deal" opens a new pattern of cross-border e-commerce, China Business. (8), pp.38-39.

[4] Kedi, Song, 2018. Research on the obstacles and countermeasures of cross-border e-commerce development in China, E-commerce. (3), pp.23-25. 